"This is a post-peer-review, pre-copyedit version of an article published in Social Indicators Research, 2017. The final authenticated version is available online at: http:// dx.doi.org/10.1007/s11205-016-1447-6".

\title{
A new multidimensional approach to measuring precarious employment $^{1}$
}

\author{
Carmelo García \\ University of Alcalá \\ Mercedes Prieto \\ University of Valladolid \\ Hipólito Simón \\ University of Alicante-IEI-IEB
}

\begin{abstract}
This article proposes a new methodology to measure precarious employment with a multidimensional approach. The adjusted multidimensional precariousness rate employed to measure job precariousness is calculated on a counting approach and exhibit several advantages, including its decomposability according to the relative contribution to total precariousness of different dimensions and sub-populations. For illustrative purposes, the methodology is applied to the Spanish case using microdata from the Encuesta de Estructura Salarial (Wage Structure Survey) and considering three precariousness dimensions of jobs (low wages, fixed-term contracts and part-time work). The evidence obtained shows that at the beginning of the economic crisis there was an increase in the incidence and intensity of precariousness for new jobs created in the Spanish economy. Moreover, obtained evidence shows that the incidence of precarious employment is particularly high in certain economic sectors and for females.
\end{abstract}

Keywords: Precarious employment, labour market, counting approach.

JEL codes: J20, J21, J28, J80.

\footnotetext{
${ }^{1}$ This study has received funding from Spain's Ministry of Economy and Competitiveness (project CSO2014-55780-C3-2-P ) and from Autonomous Community of Madrid and European Comission (project S2015/HUM-3416-DEPOPOR-CM).
} 


\section{Introduction}

The study and measurement of the quality of jobs has been the subject of recurrent debate within the major international institutions (see, for example, OECD, 2013a, 2015a and UNECE, 2014). As a result, the economic policy guidelines recently issued by these institutions not only focus on the creation of more jobs, but also on the creation of better jobs.

This contrasts with the recent proliferation of precarious, low productivity jobs, particularly in those countries affected by the recent international economic crisis (see, for example, Olsthoorn, 2014), which increase the vulnerability of economies oriented towards controlling global macroeconomic results and not towards resolving the quality, well-being, fairness and sustainability problems of their economic system (OECD, 2015a and 2015b). It is worth highlighting that to the traditional lack of attention given to the objective of improving the quality of jobs has greatly contributed the difficulty in defining and measuring the quality or precariousness of jobs in a homogeneous and generally accepted way. These concepts, which have an inherent and complex multidimensional nature, are difficult to define and quantify in practice (Clark, 2005).

This article proposes a new methodology to measure precarious employment based on the use of techniques previously used in the literature for measuring multidimensional poverty. In this regard, it is worth pointing out that our research connects to a series of previous studies that have successfully used techniques for measuring well-being in order to innovatively apply them to the analysis of the labour market (see, for example, Gradín et al. 2012).

The method used in the research for measuring the precariousness of jobs comprises a procedure for identifying precarious jobs and another aggregating procedure for summarising the multidimensional information of the precariousness in a single scalar measure (Sen, 1976). The advantage of the proposed indicators is that they measure not only the incidence (how many precarious jobs there are) but also the intensity (how many precariousness dimensions the jobs have) of the precariousness of total employment or of a specific group of it.

The method used for identifying precarious jobs is established around two types of thresholds. One is used to identify jobs with disadvantages in each of the dimensions of precariousness considered and the other is used to determine whether a job is precarious from a multidimensional perspective, considering all the dimensions. With respect to the method of aggregation, although for comparative purposes the results of other common indicators are shown in this type of analysis, this study has opted to adapt the adjusted multidimensional poverty rate, an indicator proposed by Alkire and Foster (2007 and 2011), and called the adjusted multidimensional precariousness rate for our case. This indicator simultaneously measures the incidence and intensity of the precariousness of employment. Furthermore, it is a decomposable indicator, enabling it to enrich the overall results with information about the contribution to the total precariousness of each of the precariousness dimensions and sub-populations considered. In addition, it is worth pointing out that the method used allows us to consider both qualitative and quantitative dimensions in the construction of the aggregate precariousness indicator. 
The approach used in this study, therefore, differs from those usually proposed in the economic literature to measure the quality or precariousness of employment, which are based on the construction of simple indicators for each dimension of quality or precariousness. These are then aggregated into a synthetic indicator (see, for example, Leschke, Watt and Finn, 2008). This latter form of measurement is based solely on the marginal distributions of the different individual dimensions without considering those aspects related to their joint distribution. Therefore it does not analyse the extent to which a person is simultaneously faced with a precarious situation on several dimensions, which is an essential aspect of the problem (Loughlin and Murray, 2013). Our proposal, on the other hand, takes into account the joint distribution of the dimensions and therefore a second threshold is introduced which determines the overall multidimensional atypical nature or precariousness of the jobs in relation to what is considered to be a standard job (Vosko, 2006).

For illustrative purposes, after the method of analysis has been described in detail, it will be applied to data corresponding to the Spanish case in the period 2006-2010. Therefore the study examines the first phase of the recent economic crisis. In this respect, it is worth highlighting that a considerable part of the study consists in using the Encuesta de Estructura Salarial (Wage Structure Survey) database to measure the precariousness of jobs, which includes large samples that are homogeneous over time and detailed information about wages and other objective dimensions of the jobs. This has enabled us to develop an objective approach when analysing the characteristics of the job positions, avoiding the technical drawbacks derived from using and aggregating results generated from the usual subjective rating scales of employee satisfaction surveys (which also usually have smaller sample sizes). The source chosen in our case has desirable properties and includes information about basic dimensions with which to measure precarious employment, including wages, types of contract (permanent or fixed-term) or type of working day (full-time or-part time).

The research is structured as follows. After this introduction, the second section discusses the different approaches used to address the concept and ways to measure job precariousness, contextualising the methodology proposed in this article within the related literature. This new methodology is explained in detail in the third section. The fourth part describes the data source used for the practical application of the technique to the Spanish case and the fifth section presents the results obtained from the analysis of employment precariousness in Spain between 2006 and 2010. The final section of the article draws the principal conclusions.

\section{Literature review}

In contrast with the significant development in research focused on measuring the quality of employment ${ }^{2}$, the measurement of the opposing phenomenon, namely job precariousness, on which this article focuses, has received much less attention from the economic literature. In the absence of a consensus regarding the concept and dimensions of precariousness (Laparra, 2006), the earliest studies initially focused on

\footnotetext{
${ }^{2}$ See, for example, European Commission (2001), Leschke, Watt and Finn, (2008), Leschke, Watt and Finn (2012), ILO (2012) and UNECE (2014), and, for the Spanish case, Iglesias et al. (2011) and Royuela et al. (2008 y 2009), among others.
} 
the quantification of the number of atypical or non-standard jobs (Quinlan et al. 2001; Vosko, 2002). A benchmark study is Rodgers and Rodgers (1989), which stated that precarious jobs were those that did not provide workers with the ability to secure a sufficient income with which to support a decent standard of living. Insecurity is also the basic characteristic on which Kalleberg's seminal works on the measurements of precariousness (2009, 2011) are focused and which Olsthoorn (2014) summarises in two dimensions: (1) insecurity due to the inability to ensure sufficient income through the wage and (2) insecurity associated to the possibility of being dismissed. These two basic dimensions of atypical jobs were conceived through the study of the values of the wage, type of contract (indefinite/fixed-term) and type of working day (full-time or part-time) variables which determine the greater or lesser probability of dismissal (Quinlan et al., 2001). Although they may sometimes be complemented with other less relevant aspects, these three basic dimensions are those which are usually considered in different studies carried out to characterise precarious employment (Kranh, 1995; Polivka, 1996; Leschke and Keune, $2008^{3}$ ).

Of the recent economic literature on precariousness also focusing on the proposal of specific indicators, we should highlight the study conducted by Olsthoorn (2014). As well as carrying out an exhaustive review of the different concepts and indicators of precariousness, this study proposes two indicators of the insufficiency of income (wages and complements) and employment instability respectively. When they overlap, the incidence of precariousness can be measured.

Following the research of Olsthoorn (2014), and in line with the conceptual bases of the afore-mentioned studies, our article develops a complementary approach to measuring precarious employment with more flexible techniques that enable us to measure both the incidence (number of precarious jobs) and intensity (number of precariousness dimensions in a job) of precariousness based on its multidimensional nature and from a relative perspective. As in previous studies, precarious employment is defined in comparison with a reference, consisting of a vector of different characteristics of a standard job of the total population of jobs (Rodgers, 1989; Fudge, 1997; Vosko 2002, 2006). In the case of this study, a standard job is characterized by a wage of more than $60 \%$ of the average wage in the economy and a permanent, full-time contract ${ }^{4}$ ).

According to previous studies, all the components considered of the vector of characteristics that define precarious jobs are clearly related to the concept of precariousness due to their connection with the higher probability of dismissal or other factors causing job insecurity (OECD, 2015b).

Hence, the first dimension, namely the receipt of low wages, has been widely examined in the literature (Olsthoorn, 2014), with a particular emphasis on the impact of this factor on the polarisation of the labour market and the subsequent effect on inequality and poverty (Barbier, 2004 and Rodgers and Rodgers, 1989). On the other hand, it has

\footnotetext{
${ }^{3}$ Leschke and Keune (2008) make the concept of precariousness operational by considering as precarious those jobs which are precarious in two of these three dimensions.

${ }^{4}$ Although other dimensions of precariousness related to undesirable working conditions could be considered, such as shift work, night work or working under dangerous conditions, which have been considered in previous studies (Rodgers, 1989; Barbier; 2004), or self-employment, which is usually connected to the partial access to or absence of social benefits such as unemployment benefit (Fudge et al., 2002; OCDE, 2015b), the limitations of the data source used in our research prevent us from doing so.
} 
also been found that the receipt of low wages is a characteristic that is strongly related to non-standard employment (OECD, 2015b), as the earners of these wages are usually situated at the lower tail of income distribution and greatly contribute to its polarisation.

With respect to the effects of the type of contract (temporary or permanent), it has been extensively documented in the literature that temporary contracts are associated to poorer working conditions than permanent contracts, including a higher probability of employees losing their jobs due to a decline in macroeconomic conditions (Holmlund and Storrie, 2002) and, very likely, to a greater risk of work accidents and lower wages (see the mixed evidence in Guadalupe, 2003 and Hernanz and Toharia, 2006 and De la Rica, 2004 and Davia and Hernanz, 2004, respectively). Moreover, in the specific case of Spain, it has been observed that they are, on the whole, involuntary (AmuedoDorantes, 2000) and are highly unlikely to be converted into permanent contracts over time (Güell and Petrongolo, 2007).

Finally, many studies for different countries also reveal how in general part-time employment is associated to poorer working conditions, including fewer opportunities for promotion (Russo and Hassik, 2008); lower pensions and social benefits (O'Connell and Gash, 2003; Houseman and Matchiko, 1998); lower wages (Hirsch, 2005) or lower job stability (Fernández-Kranz et. al., 2014). Furthermore, in the case of Spain, it is worth pointing out that, on the contrary to the situation of the majority of advanced countries, part-time employment is, on the whole, involuntary ${ }^{5}$.

\section{Methodology}

This section describes the methodology which enables us to obtain the novel measurements of precarious employment. After selecting the dimensions that define the precariousness of jobs (which, as we have indicated, in our analysis are related to the wage received and the type of contract and working day), the thresholds for identifying precarious jobs in each of the dimensions and in the multidimensional global indicator are determined in order to aggregate the different dimensions into a scalar value.

The identification of precarious jobs is based on a double threshold which separates jobs that are precarious from those that are not. For this purpose, firstly, a specific threshold is defined for each dimension below which a job is considered to comprise elements that render it as precarious. So, if $X_{i j}$ is the observation of dimension $j$ in job $i$, with $j=$ $1 \ldots D$, and $Z_{j}$ is the threshold established in dimension $j$, employment $i$ will exhibit precariousness elements in dimension $j$ if $X_{j i}<Z_{j}$. In this study, the thresholds of each simple indicator/dimension have been established by using criteria that are used in a standardised way in the literature: having a temporary contract, having a part-time job and earning an hourly wage that is lower than $60 \%$ of the median.

The second threshold $(k)$, which we will call the multidimensional precariousness line, is based on a new variable $P$, which summarises the total number of precariousness dimensions or disadvantages of each job. It is a weighted sum of the disadvantages of job in the indicators that define precariousness. For a job $i$ it is calculated as follows:

\footnotetext{
${ }^{5}$ According to Eurostat data, in 2014 approximately 64\% of all Spanish workers (70\% for men and 62\% for women) employed in part-time jobs had such type of jobs involuntarily.
} 


$$
P_{i}=\sum_{j=1}^{D} w_{j} I_{\left\{X_{i j}<Z_{j}\right\}} \quad i=1 \ldots n
$$

where $I_{\{B\}}$ is the indicator function of set $B ; w_{\mathrm{j}}$ is the weight assigned to each indicator and $n$ is the total number of jobs. The weights are standardised so that their sum equals the total number of indicators, $D$. This variable will take values between 0 and $D$, where 0 is associated to a job that is not considered to be precarious in any dimension and $D$ is associated to a job that is considered to be precarious in all dimensions. The weightings $w_{j}$ enable each dimension to be weighted in accordance with the importance that is attributed to it. In our case, all of the dimensions are weighted equally and the variable $P$ will be the total number of precariousness dimensions of a job (taking values between 0 and 3$)$.

The second multidimensional precariousness threshold enables us to classify jobs as precarious or not depending on the value of $P$ in each of them. Therefore, a job $i$ is precarious from a multidimensional point of view if the value of $P$ is greater than or equal to the threshold $\left(P_{i} \geq k\right)$. This article contemplates different multidimensional thresholds, established between two extreme values. On the one hand, a job may be considered to be precarious if it exhibits precariousness dimensions in one of the indicators, $k=1$ (union approach). On the other, a job may be considered to be precarious if it exhibits precariousness dimensions in all of the indicators, $k=D$ (intersection approach). The use of a threshold interval enables a sensitivity analysis to be carried out of the results obtained in the case of changes in the chosen threshold.

Although studying the values and the distribution of variable $P$ in the total population is interesting in itself, when analysing precariousness it is especially interesting to summarise the information of variable $P$ using certain indicators drawn from the field of multidimensional poverty analysis. In this way, it should be pointed out that the measurements described below are suitable for dimensions characterised by both quantitative and qualitative variables.

The first way of summarising the information of variable $P$ of precarious jobs is to calculate the rate of precariousness, $H$,

$$
H=\frac{\sum_{i=1}^{n} I_{\left\{P_{i} \geq k\right\}}}{n}=\frac{q}{n}
$$

where $q$ is the number of jobs which have a value of the variable $P$ that is greater than or equal to the established threshold $\left(q=\sum_{i=1}^{n} I_{\left\{P_{i} \geq k\right\}}\right)$. This measurement seeks to reflect the incidence of precariousness, in other words, how many precarious jobs there are, although this does not take the intensity into account, or the number of precariousness dimensions that the precarious jobs have. If the number of precariousness dimensions of a specific precarious job increases, the value of this indicator remains unchanged.

Alternatively, two measurements related to the intensity of precariousness are distinguished; the average value of variable $P$ of the multidimensional precarious jobs, $\mu_{P}^{q}$ 


$$
\mu_{P}^{q}=\frac{\sum_{i=1}^{n} P_{i} I_{\left\{P_{i} \geq k\right\}}}{\sum_{i=1}^{n} I_{\left\{P_{i} \geq k\right\}}}
$$

and the standardisation of the previous average in accordance with the number of dimensions, $A$,

$$
A=\frac{\mu_{P}^{q}}{D}
$$

Finally, a highly interesting measurement is what we have called the adjusted multidimensional precariousness rate $\left(M_{0}\right)$, introduced by Alkire and Foster (2007 and 2011) in the field of multidimensional poverty. It is defined as:

$$
M_{0}=\frac{\sum_{i=1}^{n} P_{i} I_{\left\{P_{i} \geq k\right\}}}{n D}=\frac{q}{n} \frac{\mu_{P}^{q}}{D}=H \cdot A
$$

The adjusted multidimensional precariousness rate calculates the total weighted sum of the precariousness dimensions of the jobs considered to be precarious divided by the maximum number of precariousness dimensions that all of the jobs $(n D)$ could experience. This measurement has a number of desirable properties (see Alkire and Foster, 2007 and 2011), including the fact that it takes into account both the incidence (how many precarious jobs there are) and the intensity (in how many dimensions the jobs are precarious) of the precariousness ${ }^{6}$. Furthermore it can be broken down into subgroups in terms of population and dimensions. The decomposability into $S$ subpopulations enables us to express $M_{0}$ as a weighted sum of the adjusted multidimensional precariousness rates of each subgroup:

$$
M_{0}=\sum_{l=1}^{s} \frac{n_{l}}{n} M_{0 l}
$$

where $n_{l}$ is the size of the subpopulation $l$ and $M_{o l}$ is the adjusted multidimensional precariousness rate of this subpopulation.

The decomposition into dimensions enables us to express the adjusted multidimensional precariousness rate as:

$$
M_{0}=\sum_{j=1}^{D} \frac{w_{j} H_{j}}{D}
$$

where $H_{j}$ is the proportion within the total population of precarious jobs with precariousness elements in dimension $j$.

These properties allow us to detect the existence of different precarious situations within the different subgroups of the population analysed (such as men and women or different sectors of activity), and to identify those with better and worse situations. They also

\footnotetext{
${ }^{6}$ The concept of the intensity of precariousness used in this article refers to the number of precariousness dimensions in precarious jobs (Alkire and Foster 2011b). In this respect, $M_{0}$ overcomes one of the shortcomings of the multidimensional precariousness rate $\mathrm{H}$, namely that this measure does not increase when the number of precariousness dimensions of the jobs increases.
} 
inform us of which dimensions should be given most attention in terms of economic policy measures that seek to alleviate or eliminate precarious employment.

The choice of a specific threshold or a specific index introduces certain arbitrariness in the comparisons of the indicators of precariousness. For this reason, when applying the methodology, sensitivity analyses of the results are carried out based on the results of Lasso de la Vega (2010) and Alkire and Foster (2011a) which guarantee the robustness of the comparisons of the indicators under different thresholds and which are closely related to first order stochastic dominance analyses. These results, which are used to examine the precariousness of employment in the Spanish case, guarantee that if the quantile function of variable $P$ of a population $\mathrm{B}$ is higher than the quantile function of this variable of another population A, then for any fixed threshold $k$ of multidimensional precariousness, both the proportion of precarious jobs and the adjusted precariousness rate will be greater than or the same in population $\mathrm{B}$ as in population $\mathrm{A}$.

\section{Data}

The microdata used in the empirical part of the research have been drawn from the two most recent available waves, corresponding to 2006 and 2010, of the Encuesta de Estructura Salarial (Wage Structure Survey; hereafter, EES). This survey is carried out by Spain's National Institute of Statistics and constitutes Spain's sample of the Structure of Earnings Survey, a survey which is undertaken in all the member states of the European Union according to a harmonised methodology. One of its most salient features is the inclusion of matched employer-employee microdata (that is, observations of several employees in each establishment). This type of data has, in general, had a highly significant impact on the analysis of wage determination (Hamermesh, 2008 and Abowd and Kramarz, 1999) and in the case of Spain has been widely used to analyse different characteristics of the Spanish wage structure (see for example Card and De la Rica, 20082006, Carrasco et al., 2014 and Casado and Simón, 2015).

The EES is a survey carried out among companies on a national level. It comprises a two-stage sampling of employees based on the Social Security contribution accounts of their companies. The most recent waves of the survey cover employees registered with the Social Security during the whole of the month of October of the year of reference of companies of any size affiliated to the General Social Security Scheme engaged in an economic activity included in sections B to S of the sector classification CNAE-2009. Therefore, it covers practically the whole of the private sector of the Spanish economy (with small exceptions such as agriculture or certain branches of services such as domestic service $)^{7}$. The survey is formed by independent cross sections which are developed every four years. Currently, there are four waves available corresponding to the years 1995, 2002, 2006 and 2010. The analysis conducted in this article is limited to the last two waves as the first two do not cover establishments with less than 10 workers, and these a type companies represent a very significant weight in the production and employment structure of the Spanish economy.

The EES is a survey that provides diverse information about the characteristics of the workers (wage, nationality, sex, age and educational level); their job positions (profession, seniority, type of contract, type of working day and undertaking of

\footnotetext{
7 The wave of 2010 also covers the branch of activity corresponding to Public Administration and defence and obligatory Social Security.
} 
supervisory tasks) and their firms (sector of activity, size, type of collective agreement and region).

In order to approximate the quality of jobs three indicators have been used. The first is related to the receipt of low wages, understood as being the hourly wage of the worker lower than the $60 \%$ of the median hourly wage of the economy ${ }^{8}$. The second indicator measures whether the individual has a fixed-term contract (the alternative is a permanent contract). Finally, the third indicator measures whether the individual works part-time (the alternative is that he/she works full-time) ${ }^{9}$.

With respect to the empirical analysis, those observations which do not offer information about the principal variables of interest, and those corresponding to individuals over the age of 65 have been eliminated. Furthermore, in order to use a homogeneous sectoral coverage, in the wave of 2010, those observations corresponding to section $\mathrm{O}$ of the classification CNAE-2009 (Public Administration and defence; obligatory Social Security) have not been considered. The final samples comprise 140,331 employees for 2006 (82,800 men and 57,531 women) and 171,743 employees for 2010 (99,338 men and 72,405 women). Descriptive statistics of these samples can be found in table A.1 of Appendix.

\section{Results}

\subsection{General analysis}

As previously mentioned, the novel methodology proposed has been applied to the data of the EES to analyse the evolution of precarious employment in Spain between 2006 and 2010, a period which encompasses the first stage of the economic crisis in Spain, including the Great Recession.

In order to contextualise the analysis, it is worth pointing out that after a prolonged phase of economic growth which began in the mid-1990s, the Spanish economy was very affected in 2008, similarly to other advanced countries, by the international economic crisis which gave rise to the Great Recession and in subsequent years, by the serious problems that severely affected the peripheral economies of the euro zone, including Spain. All of this gave rise to a significant and uninterrupted fall in GDP between 2009 and 2013, with the exception of 2010, when growth was zero. In this recessionary context there were very heavy job losses which were aggravated by the fact that, due to the institutional characteristics of the Spanish labour market, the Spanish economy is characterised by one of the highest elasticities of employment with respect to GDP of the advanced countries, to the extent that the unemployment rate exceeded 27\% (more details about the evolution of the Spanish labour market can be found in Banco de España, several years). The heavy job losses in the crisis context were particularly concentrated among fixed-term workers, to the point that the Spanish

\footnotetext{
8 The hourly wage has been calculated using the wage corresponding to a representative month of reference of the year in which the survey was carried out (October), divided by the number of hours worked in this month. It is expressed in gross terms and its calculation includes any type of payment made by the companies, including commissions, bonuses for night work and weekends and overtime pay.

${ }^{9}$ Part time work carried out by the workers is indicated in the EES for each company, as in the case of each worker either part-time work or full-time work was chosen as a response to the following question: "4.1 Type of working day. Part-time work is considered to be shorter than a normal working day of the company or in the case where this does not exist, shorter than the legal maximum hours established (it should be stipulated in the contract)".
} 
temporality rate dropped from levels of over 30\% before the crisis (the highest level of all advanced countries) to levels slightly over $20 \%$ after the crisis.

On the other hand, with respect to the recent evolution of wages in Spain, it should be highlighted that they did not decrease in the initial stages of the crisis due to the inertia of the wage determination mechanism derived from the characteristics of collective bargaining (with a high incidence of multi-annual agreements and clauses in the sector agreements to safeguard against unexpected rises of inflation). Therefore, the wage devaluation that has taken place recently in the Spanish economy to adjust for the accumulated losses of competitiveness with respect to the rest of the Euro zone has occurred only in the last few years, particularly after the intense labour reform of 2012 (and in any event outside of the period analysed in the research).

Finally, it is worth pointing out that part-time employment in Spain has been increasing uninterruptedly in relative terms since the beginning of the crisis (in 2006 it represented $11.8 \%$ of total employment; in 2010 it accounted for $13.0 \%$ and in 2014 it had risen to $15.9 \%)$, due to, among other circumstances, legal changes which had facilitated its use. In this vein, it is worth noting that there has been also a very significant increase in involuntary part-time work (34\% of total part-time work in 2006; 50\% in 2010 and 64\% in 2014).

All of these circumstances are reflected in the samples of the EES (Table A.1 of the Appendix), corresponding to the total employees of the private sector. Therefore, the proportion of workers with a fixed-term contract is much lower in 2010 (21.6\% of total employees) than in 2006 (30.8\%), as a consequence of the heavy job losses in fixedterm employment during the crisis. On the other hand, the proportion of workers with comparatively low wages did not experience relevant changes between 2006 (5.9\%) and 2010 (5.4\%), which is coherent with the fact that the wage devaluation that has taken place in the Spanish economy in recent years, particularly among those workers with low wages and with new contracts, has occurred in the years after the period covered by the research. Finally, the proportion of part-time employees increased significantly in the sample (16.8\% in 2006 and $20.7 \%$ in 2010), in line with the evolution of this type of employment in the Spanish economy in recent years.

When applying the methodology, first a comparison was made of the distributions of the variable that measures the number of precariousness dimensions $(P)$ of all the employees existing in 2006 and 2010, whose quantile functions, very close after the $60^{\text {th }}$ percentile, are shown in Graph 1. Stochastic dominance tests (Beach et al. 1998; Davidson and Duclos, 2000) conclude that there are no strict dominance relations (in other words, any of the two distributions has a number of precariousness dimensions greater than the other in all of the percentiles of the range of the variable). Therefore, we cannot conclude that there has been an increase or decrease in the level of precariousness in general between the two years considered. However, analysing these functions by section, we can observe some interesting findings, such as that the number of jobs without precariousness dimensions in 2010 is higher by six percentage points than that of 2006, a circumstance which was the result of a significant reduction in the temporality rate of the Spanish economy during the period examined. 


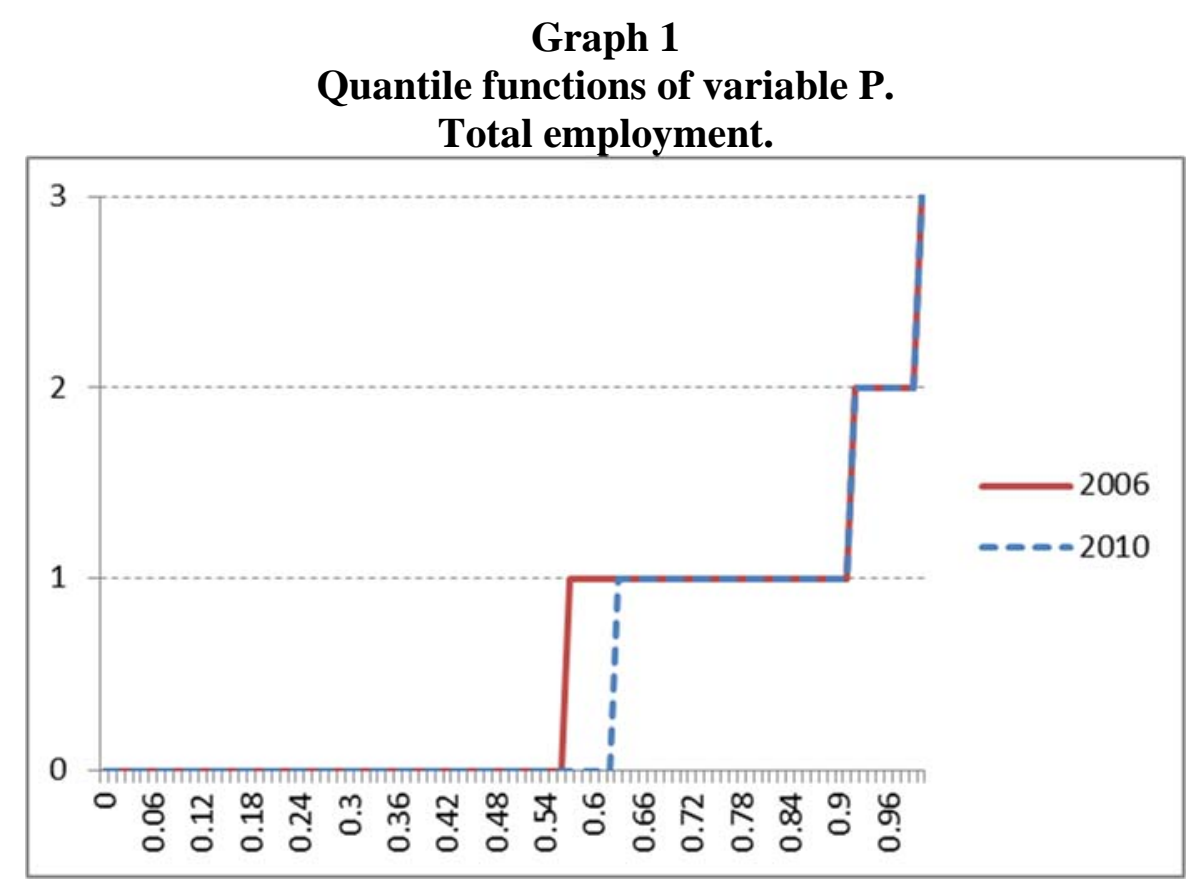

Table 1

Measurements of precariousness according to different multidimensional thresholds. Total employment.

\begin{tabular}{|c|c|c|c|c|c|}
\hline Threshold & Year & $\begin{array}{c}\text { H } \\
\text { (Rate of } \\
\text { Precariousness) }\end{array}$ & $\begin{array}{c}\text { Standard } \\
\text { error }\end{array}$ & $\begin{array}{c}\text { Mo } \\
\text { (Adjusted } \\
\text { multidimensional } \\
\text { precariousness } \\
\text { rate) }\end{array}$ & $\begin{array}{c}\text { Standard } \\
\text { error }\end{array}$ \\
\hline $\mathrm{K}=1$ & 2006 & 0.4333 & 0.0013 & 0.1782 & 0.0006 \\
\hline & 2010 & 0.3763 & 0.0012 & 0.1589 & 0.0006 \\
\hline & $\Delta 2010-2006$ & $-0.0570^{*}$ & & $-0.0193^{*}$ & \\
\hline $\mathrm{K}=2$ & 2006 & 0.0917 & 0.0008 & 0.0644 & 0.0005 \\
\hline & 2010 & 0.0926 & 0.0007 & 0.0644 & 0.0005 \\
\hline $\mathrm{K}=3$ & $\Delta 2010-2006$ & 0.0009 & & 0.0000 & \\
\hline & 2006 & 0.0098 & 0.0003 & 0.0098 & 0.0003 \\
\hline & $\Delta 2010$ & 0.0080 & 0.0002 & 0.0080 & 0.0002 \\
\hline
\end{tabular}

$(*)$ : Increase/decrease significant at $1 \%$.

When analysing the values of the measurements of precarious employments in accordance with different multidimensional thresholds, it is observed that the rate of precariousness and the adjusted multidimensional precariousness rate only increases between 2006 and 2010 for one threshold, $k=2$, but these increases are small and not statistically significant at conventional levels (Table 1). For the rest of the thresholds, we can observe a significant decrease in the measurements in 2010, which indicates a reduction in precariousness for $k=1$ and $k=3$. This reduction may be due to the fact that during these four years a quantity adjustment in the Spanish labour market took place and the most precarious jobs existing at the beginning of the crisis were lost in greater numbers, particularly those with fixed-term contracts. Therefore, the jobs that had the greatest weight in total employment in 2010 were those that had a better position in the characteristics measured in this study. 
Therefore, it is interesting to limit the analysis to jobs that were being created in the Spanish economy in the years when the surveys were carried out (2006 and 2010) to gain a clearer picture of what happened in these subpopulations that represented a smaller but more interesting part of the existing total employment. So, a subpopulation composed of recently-created jobs, defined as those with tenure in the current firm lower than two years, is considered.

Focusing now on the results obtained for the recently-created jobs, the analysis of the two quantile functions of variable $\mathrm{P}$ (Graph 2) reveals the strict dominance of the function of 2010 over that of 2006, applying the afore-mentioned stochastic dominance tests. This result is conclusive in the ordering of the overall multidimensional precariousness levels between the two years. Therefore, for any fixed threshold (the same for the two years) we will always obtain values for the precariousness rate and the adjusted multidimensional precariousness rate that are higher in 2010 than in 2006 (Alkire and Foster, 2011a). Furthermore, in accordance with the results of Lasso de la Vega (2010), we will also obtain higher values of the adjusted multidimensional precariousness rate in 2010 than in 2006. Therefore, we can conclude that there was an overall worsening of the quality of recently created employment in Spain between these two periods, irrespective of the threshold established to determine the precariousness from a multidimensional point of view.

\section{Graph 2}

Quantile functions of variable $P$. Job positions with less than two years of tenure in the firm.

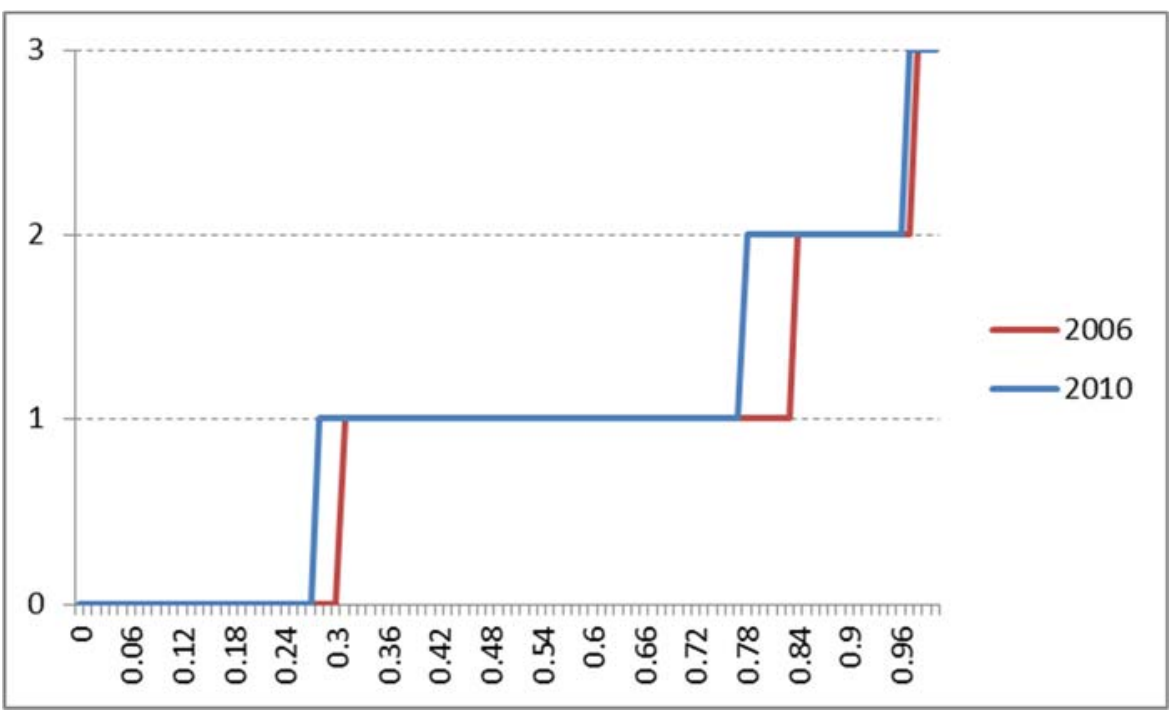

When analysing other aspects of the distribution of variable $P$ for recent jobs, it is observed that the number of jobs without precariousness dimensions falls significantly in 2010 relative to 2006, although the jobs with 1, 2 or 3 precariousness dimensions increase. This process went hand in hand with a considerable increase in the average of variable P. Consistently, according to the existing dominance of the quantile functions, the values of the multidimensional poverty indicators in Table 2 reflect increases between the two years, particularly if we take the $k=2$ threshold, where the percentage of precarious jobs increases by more than seven percentage points. In any event, it is worth pointing to that all of the variations between 2006 and 2010 in the proportion of precarious jobs and the adjusted precariousness rate, for all of the thresholds, are 
statistically significant as shown by the values of the respective statistical tests (Table 2).

Table 2

Measurements of precariousness according to different multidimensional thresholds. Job positions with less than two years of tenure in the firm.

\begin{tabular}{|c|c|c|c|c|c|}
\hline Threshold & Year & $\begin{array}{c}\mathbf{H} \\
\text { (Rate of } \\
\text { precariousness) }\end{array}$ & $\begin{array}{c}\text { Standard } \\
\text { error }\end{array}$ & $\begin{array}{c}\text { Mo } \\
\text { (Adjusted } \\
\text { precariousness } \\
\text { rate) }\end{array}$ & $\begin{array}{c}\text { Standard } \\
\text { error }\end{array}$ \\
\hline $\mathrm{K}=1$ & 2006 & 0.6975 & 0.0020 & 0.2926 & 0.0010 \\
& 2010 & 0.7188 & 0.0023 & 0.3212 & 0.0013 \\
\hline $\mathrm{K}=2$ & $\Delta 2010-2006$ & $0.0213^{*}$ & & $0.0285^{*}$ & \\
\hline & 2006 & 0.1611 & 0.0016 & 0.1138 & 0.0011 \\
& 2010 & 0.2197 & 0.0021 & 0.1548 & 0.0015 \\
\hline $\mathrm{K}=3$ & $\Delta 2010-2006$ & $0.0586^{*}$ & & $0.0410^{*}$ & \\
\hline & 2006 & 0.0193 & 0.0006 & 0.0193 & 0.0006 \\
& 2010 & 0.0293 & 0.0009 & 0.0293 & 0.0009 \\
\hline
\end{tabular}

(*): Increase/decrease significant at $1 \%$.

Overall, this evidence shows that there has been a significant increase in the precariousness of jobs created in the initial years of the crisis (wave of the EES corresponding to 2010) with respect to those created during the growth phase preceding the crisis (wave of 2006 of the EES). On the other hand, the weight of each type of employment in total population and in total employment created (see Table A.1 in the Appendix) reveals that part-time work could be the principal dimension in which precarious employment has increased in the context of the crisis, more than the creation of fixed-term jobs, which do not represent a higher percentage in the jobs more recently created during the second period of reference.

\subsection{Disaggregated analysis by sector and gender}

As previously highlighted, the decomposable nature of the adjusted multidimensional precariousness rate allows to obtain the relative contribution of different subpopulations in determining the values obtained for the measurements of precariousness of the overall population. Making use of this advantage, the contribution of each economic sector of activity and gender to precarious employment in Spain has been examined in this subsection using multidimensional thresholds.

Upper panel of Table 3 exhibits for each sector of activity its contribution to the adjusted multidimensional precariousness rate $\left(\mathrm{M}_{0}\right)$ and its weight in overall employment in 2006 and 2010, in order to determine which sectors are particularly responsible for the aggregated precariousness. According to this evidence, there are very significant differences in the relative contribution of the different sectors considered and these differences arise not only because of sectoral differences in the contribution to total employment but also because of the presence of significant differences among sectors in the intensity and incidence of precarious employment.

Although for certain sectors (retail, transport and communications and healthcare) the individual contribution of the sector to overall precariousness is rather similar to its relative weight in overall employment for some sectors (hotel and catering, other social 
activities and services, education and real estate and leasing activities) the individual contribution to overall precariousness is significantly higher than its relative weight in employment. Hence, in both years considered real estate and leasing activities was the principal generator of precarious employment in Spain (for the thresholds of precariousness established with 2 and 3 dimensions). This sector's contribution to precariousness is in every case much higher than its weight in the working population, which indicates a special incidence and intensity of the precariousness in it. As a matter of example, when the most extreme precariousness is measured (i.e. $k=3$ ), this sector represents a contribution to precariousness that is more than twice its weight in the population both in 2006 and 2010 (36.2\% and 33.9\% compared to 16.9\% and 15.1\%, respectively) ${ }^{10}$ and around one third of total precariousness. In the same vein, the contributions to precariousness by the hotel and catering and education sectors and other social activities and services are always higher than their weight in the population, which highlights the special incidence and intensity of precariousness in these sectors (in particular in other social activities and services given that, when considering the maximum number of precariousness dimensions, the contribution of the sector to total precariousness is higher than $10 \%$ compared to a weight in the employment around $3 \%$ in both years). Overall, the contribution of the aforementioned four sectors more than doubles its weight in total employment in both years (63.1\% compared to $31.6 \%$ and $30.4 \%$, respectively).

Table 3

Contribution of sectors of activity and gender to the adjusted multidimensional precariousness rate.

\begin{tabular}{|c|c|c|c|c|c|c|c|c|}
\hline & \multicolumn{4}{|c|}{2006} & \multicolumn{4}{|c|}{2010} \\
\hline & \multirow{2}{*}{$\begin{array}{c}\text { Weight } \\
\text { in total } \\
\text { empl. } \\
(\%)\end{array}$} & \multicolumn{3}{|c|}{$\begin{array}{c}\text { Relative } \\
\text { contribution to } \mathbf{M}_{0} \\
(\%) \\
\end{array}$} & \multirow{2}{*}{$\begin{array}{c}\text { Weight } \\
\text { in total } \\
\text { empl. } \\
(\%)\end{array}$} & \multicolumn{3}{|c|}{$\begin{array}{c}\text { Relative } \\
\text { contribution to } \mathbf{M}_{\mathbf{0}} \\
(\%) \\
\end{array}$} \\
\hline & & $\mathbf{K}=\mathbf{1}$ & $K=2$ & $\mathbf{K}=3$ & & $\mathbf{K}=\mathbf{1}$ & $K=2$ & $\mathbf{K}=\mathbf{3}$ \\
\hline \multicolumn{9}{|l|}{ Sector of activity } \\
\hline Extractive industries & 0.16 & 0.10 & 0.03 & 0.03 & 0.13 & 0.09 & 0.05 & 0.00 \\
\hline Manufacturing industry & 13.93 & 7.17 & 5.33 & 3.22 & 17.79 & 10.14 & 9.45 & 4.66 \\
\hline Prod. Electrical energy, gas and water & 0.17 & 0.03 & 0.02 & 0.04 & 0.89 & 0.68 & 0.56 & 0.36 \\
\hline Construction & 18.71 & 22.65 & 8.18 & 5.39 & 9.82 & 9.78 & 3.62 & 3.94 \\
\hline Retail & 18.84 & 15.51 & 16.57 & 15.29 & 25.23 & 22.40 & 21.91 & 16.47 \\
\hline Hotel and catering & 7.24 & 8.54 & 9.57 & 8.47 & 8.07 & 11.70 & 12.42 & 13.90 \\
\hline Transport and communications & 5.00 & 3.90 & 4.22 & 5.67 & 2.99 & 1.57 & 1.39 & 2.52 \\
\hline Financial intermediation & 3.22 & 0.58 & 0.50 & 0.33 & 3.02 & 0.86 & 0.84 & 0.21 \\
\hline Real estate and leasing activities & 16.90 & 22.76 & 32.05 & 36.17 & 15.14 & 20.89 & 25.58 & 33.89 \\
\hline Education & 4.54 & 6.20 & 8.60 & 4.99 & 3.51 & 6.08 & 7.94 & 4.72 \\
\hline Healthcare & 8.35 & 8.02 & 7.67 & 6.93 & 9.70 & 10.01 & 8.73 & 8.68 \\
\hline Other social activities and services & 2.95 & 4.52 & 7.24 & 13.47 & 3.71 & 5.79 & 7.50 & 10.64 \\
\hline \multicolumn{9}{|l|}{ Gender } \\
\hline Women & 41.50 & 51.45 & 66.81 & 71.75 & 45.62 & 58.39 & 64.01 & 76.38 \\
\hline Men & 58.50 & 48.55 & 33.19 & 28.25 & 54.38 & 41.61 & 35.99 & 23.62 \\
\hline
\end{tabular}

\footnotetext{
${ }^{10}$ Note that in terms of evolution over time the contribution of the sectors to precarious employment tends to adapt in general to the restructuring of the population weights in the jobs during the period of economic crisis considered.
} 
Conversely, for a significant number of sectors (extractive industries, manufacturing industry, production of electrical energy, gas and water, construction and financial intermediation) the individual contribution to overall precariousness is much lower than its relative weight in employment. Hence, for example, despite of the significant weight in total employment in the Spanish economy of the manufacturing industry and the construction sector (32.6\% in 2006 and $27.6 \%$ in 2010) their aggregate impact in total precariousness is rather low $(8.6 \%$ and $8.5 \%$ when considering the most extreme case of precariousness, with $\mathrm{k}=3$ ). In a similar manner, the contribution to overall employment precariousness of the extractive industries, production of electrical energy, gas and water and financial intermediation sectors is significantly lower than their relevance in total employment. As a result, the joint contribution to precariousness of the said five sectors is three to four times their overall weight in total employment both in 2006 and 2010 (36.2\% and 31.6\% compared to 9\%\% and 9.2\%, respectively).

On the other hand, the relative contributions to the indicator of precariousness, the adjusted multidimensional precariousness rate $\left(\mathrm{M}_{0}\right)$, according to gender are presented in the lower panel of Table 3. The evidence obtained indicates that the contribution to the overall precariousness of females is well above their weight in total employment and this gap increases with the threshold multidimensional poverty. Thus, although in 2006 the weight in total employment of females is significantly lower than that of males (41.5\% compared to $58.5 \%$ ) their relative contributions to total precariousness is always higher, very especially when a higher number of precariousness dimensions is considered (66.8\% with $k=2$ and $71.7 \%$ with $k=3$ ). In a similar manner, although the weight of the jobs held by women in total employment increased in 2010 (45.6\%), due to the fact that severe job losses in the initial years of the crisis particularly affected men, the conclusions are similar to those obtained in 2006, with a contribution to the extreme precariousness of jobs performed by women again more than 30 points above to its weight in total employment. All in all, this evidence overall indicates a strong intensity and incidence of precariousness in jobs held by women, especially relevant in explaining the extreme precariousness.

\section{Conclusions}

In this article a novel methodology for measuring precarious employment has been proposed based on the use of the counting approach and related multidimensional indicators derived from this approach. These tools were originally proposed for the measurement of multidimensional poverty and have been adapted here in a novel way to the field of job precariousness.

This new methodology enables us to incorporate the dimensions and simple indicators of precariousness to a logical and transparent structure which also allows different possibilities to weight the selected dimensions. The dimensions are not introduced in a hierarchical way and wherever is possible to conduct a separate study of each of them and to determine the contribution of each dimension in the overall indicator. Furthermore, it is used all of the information regarding the overall distribution of the dimensions in the individuals, who can simultaneously experience advantages and disadvantages in their work positions.

The multidimensional indicators which aggregate the information enable us to measure both the incidence and, particularly, the intensity of precariousness. The adjusted precariousness rate is also decomposable, which allows us to determine the contribution 
of different dimensions and subpopulations of interest to the general indicator of precariousness.

For illustrative purpose, the new methodology is applied to the Spanish case. The empirical evidence shows a significant increase in precariousness between 2006 and 2010 in Spain for newly created jobs, irrespective of the precariousness threshold used. For total jobs, however, it is observed a reduction in precariousness during the period, which is explained by the typical quantity adjustment of the Spanish labour market, whereby recessionary contexts give rise to heavy job losses of mainly fixed-term, more precarious jobs.

On the other hand, using the decomposability property of the adjusted multidimensional precariousness rate for the total jobs, a disaggregated analysis is applied in order to examine the relative impact on total precariousness of different sub-populations defined according to sector of activity and gender. In this vein, we can conclude that the precariousness existing in total jobs is particularly explained by certain sectors (hotel and catering, education, real estate activities and leasing and other social activities and services) with higher contributions to precariousness than those that correspond to them in terms of their weight in total employment. Similarly, the obtained evidence reveals that in the two years of the study jobs held by women have significantly higher contributions to total precariousness than jobs held by men despite their lower weight in the population, accentuating this fact for the explanation of the extreme precariousness. Furthermore, it is observed that, in general, the relative contributions to precarious employment of different sub-populations defined according to sector and gender have evolved in line with their weight in employment during the period of economic crisis.

\section{References}

Abowd, J.M.; Kramarz, F. (1999): “The Analysis of Labor Markets Using Matched EmployerEmployee Data”, en O. Ashenfelter and D. Card (ed.) Handbook of Labor Economics, ed. North-Holland.

Alkire, S., \& Foster, J. (2007). Counting and Multidimensional Poverty Measures. OPHI Working Paper, $n^{\circ} 7$.

Alkire, S., \& Foster, J. (2011). Counting and Multidimensional Poverty Measurement. Journal of Public Economics, 95(7-8), 476-487.

Amuedo-Dorantes, C. (2000). Work transitions into and out of involuntary fixed-term employment in a segmented market: evidence from Spain. Industrial \& Labor Relations Review, 53(2), 309-325.

Banco de España (several years): Informe anual.

Barbier, J. (2004). A comparative analysis of 'employment precariousness' in Europe. European Research Centre, Cross-National Research Papers, 7, 7-19.

Beach, C.M., K.V. Chow, J.P. Formby and G.A. Slotsve (1994): "Statistical inference for decile means”, Economic Letters, vol. 45, n. ${ }^{\circ}$ 2, 161-167.

Card, D.; de la Rica, S. (2006): "Firm-level Contracting and the Structure of Wages”, Industrial and Labor Relations Review, vol. 59(4), 573-593.

Carrasco, R., J. F. Jimeno, and A. Carolina Ortega (2014): "Returns to Skill and the Distribution of Wages: Spain 1995-2006”, Oxford Bulletin of Economics and Statistics, doi: 10.1111/obes.12077.

Casado J.M.; Simón, H. (2015): "La evolución de la estructura salarial (2002-2010)”, Revista de Economía Aplicada, Vol. XXII(67), 5-43. 
Clark, A. (2005). Your money or your life: Changing job quality in OECD countries. British Journal of Industrial Relations, 43(3), 377-400.

Davia, M.A. and Hernanz, V. (2004): "Temporary employment and segmentation in the Spanish labour market: An empirical analysis through the study of wage differentials", Spanish Economic Review, 6(4), 291-318.

European Commission (2001). "Employment in Europe”, Luxembourg: http://ec.europa.eu/employment_social/employment_analysis/eie/2001_en.pdf

Davidson, R., \& Duclos, J. Y. (2000). Statistical inference for stochastic dominance and for the measurement of poverty and inequality. Econometrica, 68(6), 1435-1464.

De la Rica, S. (2004). Wage gaps between workers with indefinite and fixed-term contracts: The impact of firm and occupational segregation. Moneda y Crédito, 219(1), 43-69.

Eurofound (2007) The Flemish Workability Monitor: A Broad Focus on Quality of Work, Dublin: The European Foundation for the Improvement of Living and Working Conditions. Eurostat, Data Navigation Tree: http://epp.eurostat.cec.eu.int/

Fernández-Kranz, D.; Paul, M. and Rodríguez-Planas, N. (2014): "Part-Time Work, Fixed-Term Contracts, and the Returns to Experience”, Oxford Bulletin of Economics and Statistics, forthcoming, http://dx.doi.org/10.1111/obes.12073. 512-541.

Fudge, J., Tucker, E. and Vosko, L. (2002). The legal concept of employment: Marginalizing workers. Report for the Law Commission of Canada. Ottawa.

García Pérez, J. I. and M. Jansen (2015). Reforma Laboral de 2012. ¿Qué sabemos sobre sus efectos y qué queda por hacer?, Fedea Policy Papers - 2015/04

Guadalupe, M. (2003). The hidden costs of fixed term contracts: the impact on work accidents. Labour Economics, 10(3), 339-357.

Güell, M., \& Petrongolo, B. (2007). How binding are legal limits? Transitions from fixed-term to permanent work in Spain. Labour Economics, 14(2), 153-183.

Hamermesh, D. (2008): "Fun with matched firm-employee data: Progress and road maps", Labour Economics, vol. 15(4), 662-672.

Hernanz, V. and Toharia, L. (2006): "Do temporary contracts increase work accidents? A microeconometric comparison between Italy and Spain", Labour. Review of Labour Economics and Industrial Relations, 20(3), 475-504.

Hirsch, B.T. (2005): "Why do Part-Time Workers Earn Less? The Role of Workers and Job Skills”, Industrial and Labor Relations Review, Vol. 58, Nº. 4, 525-551.

Holmlund, B., \& Storrie, D. (2002). Fixed-term work in turbulent times: the Swedish experience. The Economic Journal, 112(480), F245-F269.

Houseman, S. and O. Machiko (1998): "What is the Nature of Part-Time Work in the United States and Japan?"' in O'Reilly, J. and C. Fagan (eds.), Part-Time Prospects: An International Comparison of Part-Time Work in Europe, North America, and the Pacific Rim,. Routledge, 232-251.

Iglesias, C.; Llorente, R.; Dueñas, D. (2011). Calidad del empleo y satisfacción laboral en las regiones españolas. Un estudio con especial referencia a la Comunidad de Madrid, Investigaciones Regionales, 19, 25-49.

ILO (2004) Economic Security for a Better World, Geneva: ILO.

Kalleberg, A. (2008). The mismatched workers: When people don't fit their jobs. Academy of Management Perspectives, 22(1), 24-40.

Kalleberg, A. (2009). Precarious work, insecure workers: Employment relations in transition. American Sociological Review, 74(1), 1-22.

Kalleberg, A. (2011). Good jobs, bad jobs: The rise of polarized and precarious employment in the United States, 1970s to 2000s. New York: Russel Sage Foundation.

Laparra, M. (2006). La construcción del empleo precario. Madrid: Fundación FOESSA, Cáritas Española Editores.

Lasso de la Vega, C. (2010). Counting poverty orderings and deprivation curves. In: Bishop, J.A. (Ed.), Studies in Applied Welfare Analysis: Papers from the Third ECINEQ Meeting, Research on Economic Inequality, Volume 18, 153-172. Emerald Group Publishing Limited, Bingley. 
Leschke, J., \& Keune, M. (2008). Precarious employment in the public and private service sectors: Comparing the UK and Germany. In M. Keune, J. Leschke, \& A. Watt (Eds.), Privatisation and liberalisation of public services in Europe: An analysis of economic and labour market impacts. Brussels: ETUI.

Leschke, J. , A. Watt and M. Finn (2012) Job quality in the crisis - an update of the Job Quality Index (JQI), Working paper 2012.07, Brussels: ETUI.

Leschke, J., Watt, A., \& Finn, M. (2008). Putting a number on job quality? Constructing a European job quality index. ETUI-REHS Working Paper, 2008.

Loughlin, C., \& Murray, M. (2013). Employment status congruence and job quality. Human Relations, 66, 529-553.

O’Connell, P.J. and V. Gash (2003): “The Effects of Working Time, Segmentation and Labour Market Mobility on Wages and Pensions in Ireland”, British Journal of Industrial Relations 41, 71-95.

OECD (2013a): It’s all about people: jobs, equality, and trust, May 2013, Paris, institutional edition.

OECD (2013b): Ministerial Council Statement, adopted at the Council at Ministerial Level on 30 May 2013, Paris, institutional edition.

OECD (2015a): Final NAEC Synthesis, Paris institutional edition.

OECD (2015b), "Non-standard work, job polarisation and inequality", in OECD, In It Together: Why Less Inequality Benefits All, OECD Publishing, Paris.

Olsthoorn, M. (2014). Measuring precarious employment: A proposal for two indicators of precarious employment based on set-theory and tested with Dutch labor market-data. Social Indicators Research, 119(1), 421-441.

Quinlan, M., Mayhew, C. and Bohle, P. (2001). The global expansion of precarious employment, work disorganisation and occupational health: A review of recent research. International Journal of Health Services, 31(2), 335-414.

Rodgers, G. (1989). "Precarious employment in Western Europe: The state of the debate." In Precarious jobs in market labour regulation: The growth of atypical employment in Western Europe. Geneva: International Institute for Labour Studies.

Rodgers, G. and Rodgers, J. (1989). Precarious jobs in labour market regulation: The growth of atypical employment in Western Europe. Geneva: ILO.

Royuela, V., J. López-Tamayo and J. Suriñach (2008). "The institutional vs. the academic definition of the quality of work life. What is the focus of the European Commission?" Social Indicators Research, 86(3), 401-415,

Royuela, V, J. López-Tamayo and J. Suriñach. (2009). "Results of a Quality of Work Life Index in Spain. A Comparison of Survey Results and Aggregate Social Indicators", Social Indicators Research, 90(2), 225-241.

Russo, G. and W. Hassink (2008): "The Part-Time Wage Gap: A Career Perspective”, De Economist, Vol. 156, No. 2, pgs. 145-74.

Sen, A., (1976): "Poverty: An Ordinal Approach to Measurement”, Econometrica, no 44 (2), pgs. 219-231.

UNECE (2014) Statistical Framework for Measuring Quality of Employment, prepared by the Expert Group on Measuring Quality of Employment. United Nations Economic Commission for Europe.

Vosko, L. (2002). Rethinking feminization: Gendered precariousness in the Canadian labour market and the crisis in social reproduction. Annual Robarts Lecture. Robarts Centre for Canadian Studies.

Vosko, L. (2006). Precarious employment: Understanding labour market insecurity in Canada. Montreal: McGill-Queen’s University Press. 


\section{Appendix}

Table A.1. Descriptive statistics.

\begin{tabular}{|l|c|c|c|c|c|c|}
\hline & \multicolumn{3}{|c|}{ Total } & \multicolumn{2}{c|}{$\begin{array}{c}\text { Jobs with two or } \\
\text { more years of } \\
\text { tenure in the firm }\end{array}$} & $\begin{array}{c}\text { Jobs with less than } \\
\text { years of tenure in } \\
\text { the firm }\end{array}$ \\
\hline & 2006 & 2010 & 2006 & 2010 & 2006 & 2010 \\
\hline Average wage & 9,397 & 10,739 & 10,714 & 11,517 & 7,603 & 8,582 \\
\hline Median wage & 7,395 & 8,555 & 8,521 & 9,276 & 6,525 & 7,251 \\
\hline \% fixed-term jobs & 30,770 & 21,580 & 10,170 & 9,080 & 58,840 & 56,270 \\
\hline \% low-wage jobs & 5,880 & 5,360 & 4,140 & 3,950 & 8,260 & 9,270 \\
\hline \% part-time jobs & 16,820 & 20,740 & 13,970 & 17,100 & 20,690 & 30,810 \\
\hline Sample sizes & 140.331 & 164.465 & 87.400 & 126.646 & 52.931 & 37.819 \\
\hline
\end{tabular}

